\title{
PROPARGYL ALCOHOL AS CORROSION INHIBITOR FOR STAINLESS STEEL 3 I7L IN 3.5 WT. \% SODIUM CHLORIDE SOLUTION
}

\author{
Fernando Benedicto Mainier ${ }^{*}$ \\ Humberto Nogueira Farneze ${ }^{2}$ \\ Laís Ferreira Serrão ' \\ Virgilio Pomponet dos Reis ' \\ Thais Pereira Sarmento '
}

\begin{abstract}
AISI 3I7L stainless steel is specified for equipment and components used in the treatment of formation water from oil and gas production with high salinity. To avoid or reduce the sodium chloride attack on stainless steel $3 / 7 \mathrm{~L}$, the corrosion inhibitor, propargyl alcohol (2-Propin-ol-I) base, is added. The corrosion inhibition effect of propargyl alcohol on AISI 3I7L stainless steel in sodium chloride solutions at $3.5 \%$ (mass) concentration and temperatures of 25,40 and $55^{\circ} \mathrm{C}$ was investigated using electrochemical (cyclic potentiodynamic) and optical microscopy methods. The laboratory results obtained to evaluate the protection of AISI 3I 7L stainless steel showed that they are very promising with the addition of propargyl alcohol in the sodium chloride solution, because it reduces the intensity of pitting on the passivated surface.
\end{abstract}

Keywords: AISI 3 I LL; Pitting; Corrosion inhibition; Propargyl alcohol.

\section{INTRODUCTION}

The use of carbon steel is reasonably common in equipment and tubing in the production of crude oil, where a three-phase separator with the addition of demulsifiers and heating $\left(60-80^{\circ} \mathrm{C}\right)$ promotes the separation of the three phases: natural gas, oil and formation water. The formation water associated with petroleum has a high concentration of soluble salts, $\sim 20-30 \%$ by weight, generally in the form of chloride $(\mathrm{Cl})$ and small amounts of sulfate $\left(\mathrm{SO}_{4}{ }^{2-}\right)$, carbonate $\left(\mathrm{CO}_{3}^{2-}\right)$ and bicarbonate $\left(\mathrm{HCO}_{3}{ }^{-}\right)$. In addition, the presence of $\mathrm{H}_{2} \mathrm{~S}$ and $\mathrm{CO}_{2}$ is also common with increased corrosiveness. Under these conditions, the corrosion of carbon steel is intense [I].

In order to mitigate or minimize the corrosive process, internal coatings (metallic, organic or composite) and corrosion inhibitors are used. However, nothing prevents corrosion problems from being remedied by replacing with more resistant materials.

In the production of gas and oil during recent years, due to the development of the technological sector, there was a significant increase in the use of new alloys, metallic coatings (Ni-P, Nickel-Phosphorus), cladding on special tools in oil production, valves and other components that have replaced traditional carbon steel.

One of the alternatives proposed in this work is the replacement of carbon steel or other austenitic stainless steels with AISI 3I7L, used either in the direct form or as a cladding in equipment, such as valves and pumps. AISI 3 I $7 \mathrm{~L}$ is characterized by having $3 \%$ molybdenum, higher than for AISI 3 I6L, which has $2 \%$ molybdenum.

The 3\% molybdenum content in this stainless steel promotes greater resistance in joints welded to the chemical attack of various products and in particular resists corrosion by pitting and crevices. The mechanical properties, particularly, fluency and mechanical strength at high temperatures, have not yet been optimized when compared with conventional stainless steels. The designation "L" $(<0.035$ carbon $)$ in AISI $317 \mathrm{~L}$ stainless steel ensures the resistance to sensitization during welding or when thermic processes are applied due to the low carbon content in the chemical composition $[2,3]$.

Generally, the passivation formed on the surface of austenitic stainless steels is spontaneous, with the formation of a continuous barrier of metallic oxides constituting the steel after exposure to the air or of other environments containing oxygen. This oxide layer is called the passive layer or the passive film. This layer has the ability to self-repair, but if it is damaged, corrosion may occur. Some acids considered being reductive, such as hydrochloric $(\mathrm{HCl})$, sulfuric $\left(\mathrm{H}_{2} \mathrm{SO}_{4}\right)$, phosphoric $\left(\mathrm{H}_{3} \mathrm{PO}_{4}\right)$ and hydrofluoric $(\mathrm{HF})$ acids, when in contact with stainless steel, totally or partially remove the protective oxide layer that gives it resistance

'Escola de Engenharia, Universidade Federal Fluminense - UFF, Niterói, RJ, Brasil.

${ }^{2}$ Centro Federal de Educação Tecnológica Celso Suckow da Fonseca, Rio de Janeiro, RJ, Brasil.

*Corresponding author: fmainier@uol.com.br

2176-1523 (C) 2020. Mainier et al. Published by ABM. This is an Open Access article distributed under the terms of the Creative Commons Attribution License, which permits unrestricted use, distribution, and reproduction in any medium, provided the original work is properly cited. 
to corrosion, resulting in the steel becoming susceptible to corrosion. Aqueous solutions containing chlorides $\left(\mathrm{Cl}^{-}\right)$ or fluorides $(\mathrm{F})$ may also cause localized damage to the passivized oxide layer [3-6].

Considering the corrosion problems encountered in the production of crude oil and in the formation water, this study proposes to evaluate the performance of stainless steel AISI 3 I $7 \mathrm{~L}$ in sodium chloride solution with and without the addition of a corrosion inhibitor in relation to the probability of pitting.

Corrosion inhibitor can be defined as a substance that added to the corrosive medium acts as a barrier between the metal surface and the corrosive medium that prevents or reduces the corrosive action of the medium itself. The inhibitor chosen was propargyl alcohol, which has good performance in the protection of AISI 3I7L in hydrochloric acid solution [3].

Considering the corrosion problems encountered in the production of crude oil and in the formation water, the main objective of this study proposes is to evaluate the performance of stainless steel AISI 3 I 7L in the 3.5\% (mass) sodium chloride solution with and without the addition of a corrosion inhibitor in relation to the probability of pitting.

\section{MATERIAL AND METHODS}

\section{I Cyclic Potentiodynamic Polarization Measurements}

Samples for this electrochemical test were made from AISI 3 I 7L stainless steel plates whose chemical analysis is presented in Table I.

The preparation of the electrodes consisted, essentially, of the sanding of samples with sanding grades of 100 to 1200. After this procedure, the samples were washed and passed through ultrasonic cleaning equipment for $3 \mathrm{~min}$, in order to remove possible residues that may have been aggregated during sanding.

After cleaning, the samples were polished, also in a polishing machine, with a I $\mu$ m alumina $\left(\mathrm{Al}_{2} \mathrm{O}_{3}\right)$ solution. Thereafter, they were washed and completely dried with a dryer, leaving no marks on the sample surface. After drying, the sides and vertices of the sample were covered with colorless enamel to waterproof the edges. The sample exposure area used in the tests was $0.25 \mathrm{~cm}^{2}$.

Next, the samples were inserted into a conventional polarization cell with a volume of $200 \mathrm{~mL}$. The electrochemical cell used consists of a working electrode, a platinum counter electrode and a saturated calomel reference electrode. The polarization curves were recorded using a Type III Autolab potentiostat.

In the electrochemical cell was immersed a solution of $3.5 \%$ (mass) sodium chloride $(\mathrm{NaCl})$. The temperatures maintained in the cell were 25,40 and $55^{\circ} \mathrm{C}$ using a thermostatically controlled bath. For each temperature was completed a test with and another without the corrosion inhibitor. The corrosion inhibitor concentration, based on propargyl alcohol (2-propyn-ol-I), was fixed to $1 \%$ (\% volume). For each test at the temperatures referenced were made 4 coupons of stainless steel AISI 3 I 7 L.

The scanning started from the open circuit potential $\left(\mathrm{E}_{\mathrm{OCP}}\right)$, with a rate of $\mathrm{I} \mathrm{mV} / \mathrm{s}\left(\mathrm{V}_{\mathrm{SCE}}\right.$, saturated calomel electrode). The potential was reversed when the current density reached $\mathrm{I} \mathrm{mA} / \mathrm{cm}^{2}$. The program resulted in potential and current variation data. These data were treated in order to obtain the current density and the potential modulus, guaranteeing only the use of positive values.

For the pitting potential $\left(\mathrm{E}_{\mathrm{PIT}}\right)$ determination, a plot of the potential versus density was plotted. Generally, the pitting potential is given at the point where there is an abrupt increase in current density. The repassivation potential $\left(E_{\text {REP }}\right)$ was considered at the meeting point of the anodic and cathodic scan curves. The passivation interval is represented by the difference between the pitting potential and the open circuit potential $\left(\mathrm{E}_{\mathrm{PIT}}-\mathrm{E}_{\mathrm{OCP}}\right)$. The parameters presented in Table 2 were calculated from the experimental data using the graphical data analyses with software Origin Pro 8.0. After each test was conducted, an analysis with an optical microscope was performed to identify pitting on the metallic surfaces.

\subsection{Pitting Identification on Sample Surfaces after Testing}

To identify the occurrence of pitting on the metallic surface, the following laboratory operations were followed. Soon after the electrochemical assays were performed,

Table I. Chemical composition of AISI 3 I7L austenitic stainless steel

\begin{tabular}{ccccccc}
\hline $\mathbf{C}(\%)$ & $\mathrm{Mn}(\%)$ & $\mathrm{Si}(\%)$ & $\mathrm{Cr}(\% 0$ & $\mathrm{Ni}(\%)$ & $\mathrm{Mo}(\%)$ & $\mathrm{Fe}(\%)$ \\
\hline 0.024 & 1.34 & 0.47 & 18.13 & 11.41 & 3.02 & balance \\
\hline
\end{tabular}

Table 2. Parameters obtained from polarization curves

\begin{tabular}{lcccc}
\hline \multicolumn{1}{c}{ Conditions } & \multicolumn{4}{c}{ Pitting Corrosion Resistance } \\
\cline { 2 - 5 } & $\mathbf{E}_{\text {OCP }}, \mathbf{V}_{\text {SCE }}$ & $\mathbf{E}_{\text {PIT }}, \mathbf{V}_{\text {SCE }}$ & $\mathbf{E}_{\text {REP }}, \mathbf{V}_{\text {SCE }}$ & $\mathbf{E}_{\text {OCP }}-\mathbf{E}_{\text {PIT }}, \mathbf{V}_{\text {SCE }}$ \\
\hline $25^{\circ} \mathrm{C}$, Without inhibitor & 0.03 & 0.94 & -0.02 & 0.91 \\
$25^{\circ} \mathrm{C}$, With inhibitor & 0.02 & 0.95 & -0.15 & 0.93 \\
$40^{\circ} \mathrm{C}$, Without inhibitor & -0.08 & 0.79 & -0.24 & 0.87 \\
$40^{\circ} \mathrm{C}$, With inhibitor & -0.09 & 0.92 & $<0.03$ & 1.01 \\
$55^{\circ} \mathrm{C}$, Without inhibitor & 0.10 & 0.77 & $<0.13$ & 0.67 \\
$55^{\circ} \mathrm{C}$, With inhibitor & -0.05 & 0.86 & $<0.06$ & 0.91 \\
\hline
\end{tabular}


the samples represented by the electrodes were placed on the ultrasound equipment so that possible deposits could be removed. Later, the samples were dried with hot air. Then, they underwent metallographic polishing with a $0.3 \mu \mathrm{m}$ alumina solution, were washed with distilled water and ethyl alcohol before being dried with hot air again. Each sample underwent metallographic etching for $20 \mathrm{~s}$ in a modified Behara reagent that was composed of $20 \mathrm{~mL}$ of hydrochloric acid $(\mathrm{HCl}), 80 \mathrm{~mL}$ of distilled water and $0.6 \mathrm{~g}$ of potassium metabisulfite $\left(\mathrm{K}_{2} \mathrm{~S}_{2} \mathrm{O}_{5}\right)[7,8]$. Finally, the samples were analyzed using an optical microscope.

\section{RESULTS AND DISCUSSION}

\section{I Potentiodynamic Cyclic Polarization Measurements}

The AISI 3I $7 \mathrm{~L}$ contains in its matrix a percentage of $3 \%$ of molybdenum which considerably increases the resistance to corrosion by pitting in solutions containing chloride $\left(\mathrm{Cl}^{-}\right)$. This type of corrosion in stainless steels occurs with the localized breaking of the passive layer that forms on the surface of these steels where the chloride

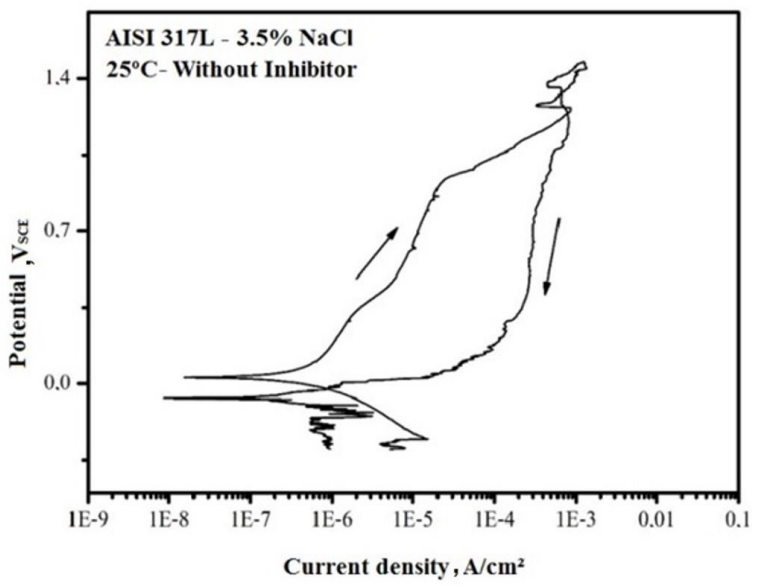

Figure I. Polarization test results at $25^{\circ} \mathrm{C}$ without corrosion inhibitor.

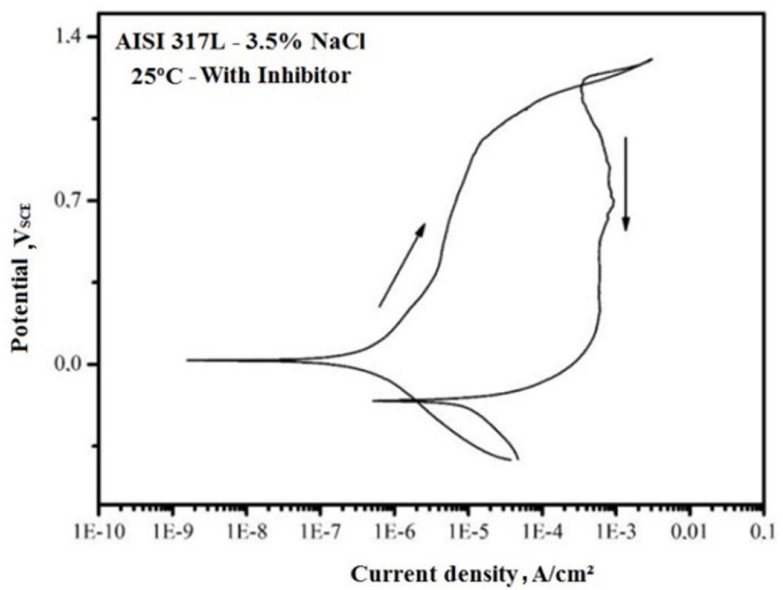

Figure 2. Polarization test results at $25^{\circ} \mathrm{C}$ with corrosion inhibitor. ion is one of the most aggressive agents. In addition, the discontinuity or imperfections of this passivated layer from mechanical damage or discontinuous formation of this film contributes in this deleterious action. According to Calle et al. [9] the formation of stainless steel pitting can be characterized by a rapid increase of current with a small change in potential.

The polarization curves generated in the cyclic potentiodynamic tests were established according to ASTM G6I-86 [10]. Figures I to 6 show the curves obtained in each case evaluated from the AISI 3I IL stainless steel and respective images of the electrodes generated by the optical microscope after the execution of each test. The parameters obtained in the polarization curves, i.e., the open circuit potential $\left(\mathrm{E}_{\mathrm{OCP}}\right)$, pitting potential $\left(\mathrm{E}_{\mathrm{PIT}}\right)$ and repassivation potential $\left(E_{\text {REP }}\right)$, are shown in Table 2. The larger the pitting potential and the passivation range, the higher the material's pitting corrosion resistance. The AISI $3 \mid 7 \mathrm{~L}$ stainless steel passivation range is represented by the difference between the pitting potential and the open circuit potential $\left(\mathrm{E}_{\mathrm{PIT}}-\mathrm{E}_{\mathrm{OCP}}\right)$.

After the analysis of the results obtained in the polarization curves of the cyclic potentiodynamic tests, it was observed that with the elevation of the test temperature,

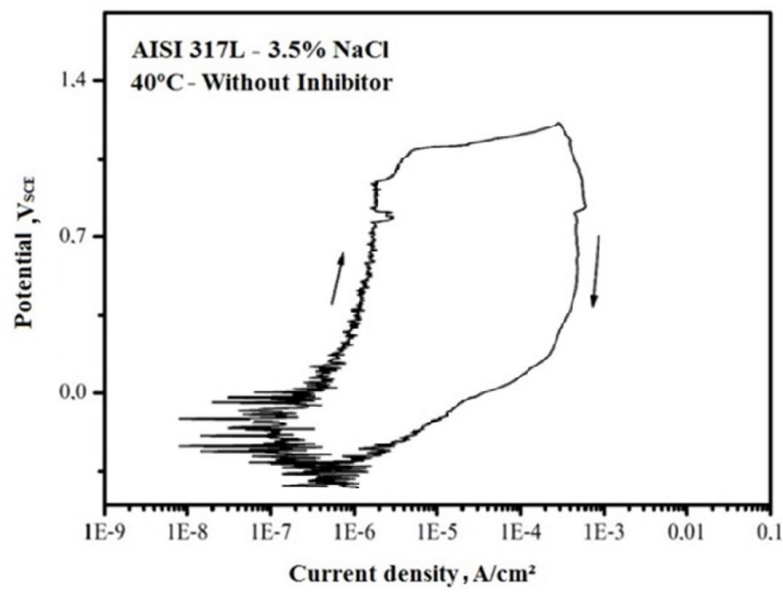

Figure 3. Polarization test results at $40^{\circ} \mathrm{C}$ without corrosion inhibitor.

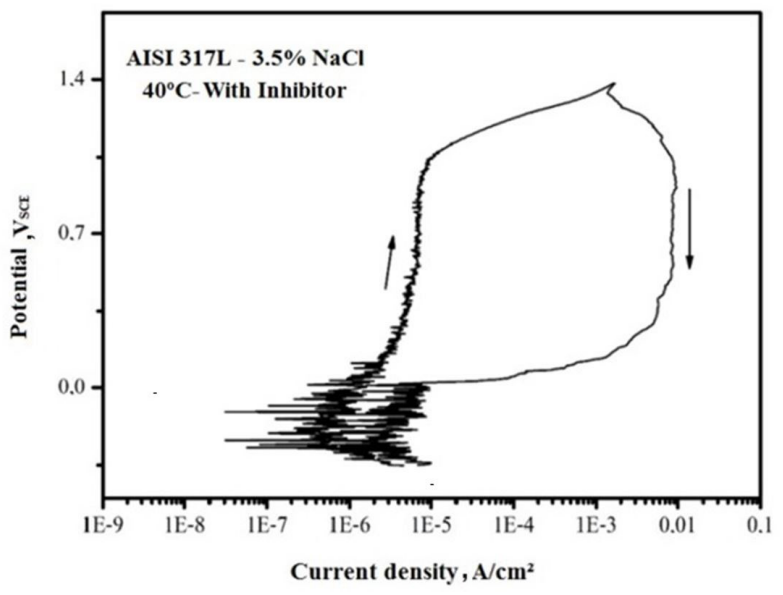

Figure 4. Polarization test results at $40^{\circ} \mathrm{C}$ with corrosion inhibitor. 


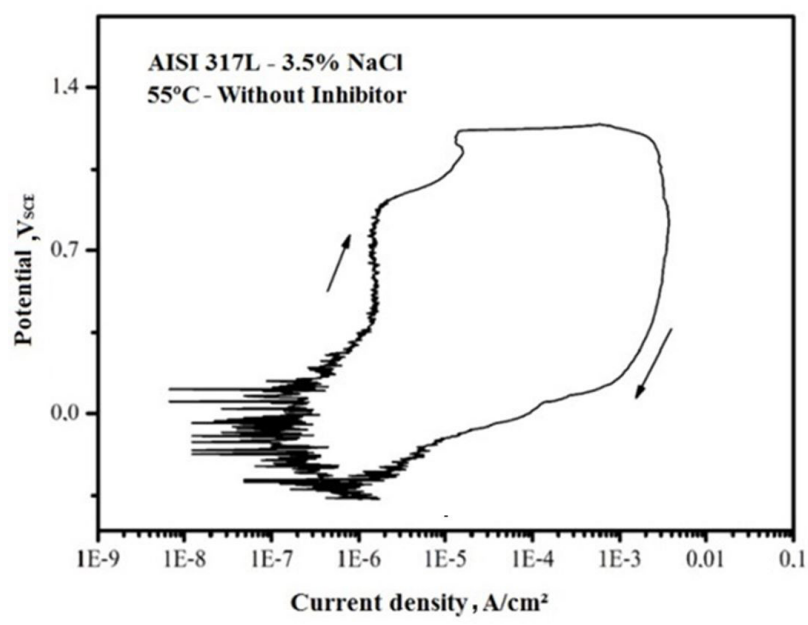

Figure 5. Polarization test results at $55^{\circ} \mathrm{C}$ without corrosion inhibitor.

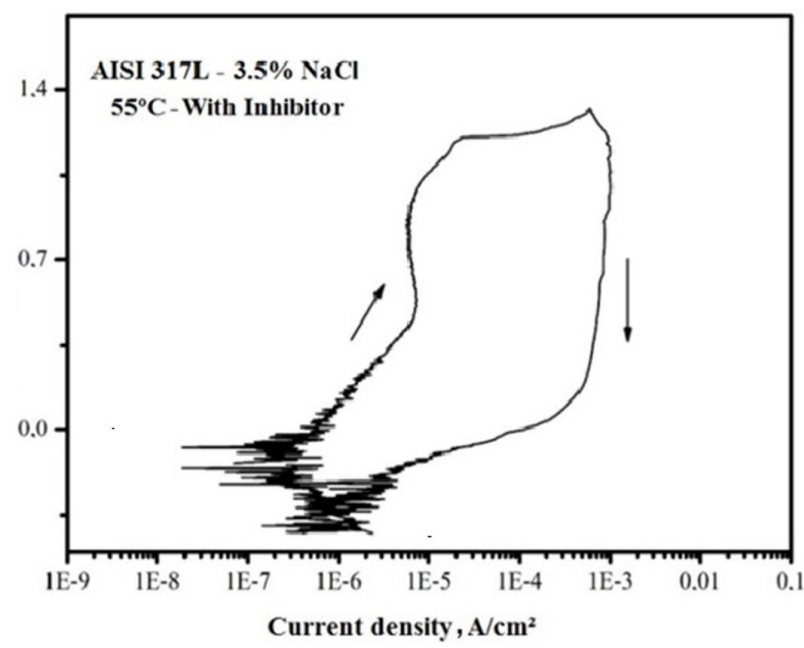

Figure 6. Polarization test results at $55^{\circ} \mathrm{C}$ with corrosion inhibitor.

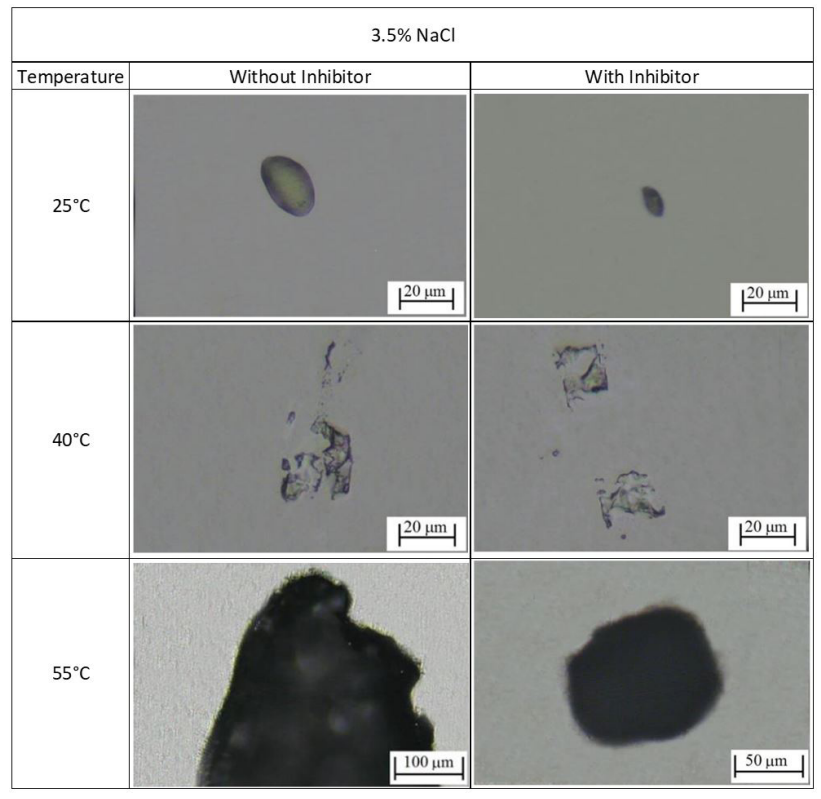

Figure 7. Microscopic analysis after polarization tests $(3.5 \% \mathrm{NaCl}$ at 25,40 and $55^{\circ} \mathrm{C}$ ). a decrease in the corrosion resistance occurs, generating an increase in the quantity and size of the pitting. For tests carried out at the same temperature, it is noticed that with the use of the corrosion inhibitor (propargyl alcohol), there is an increase in the pitting potential and the passivation interval of the material, which represents a higher corrosion resistance of the stainless steel.

\subsection{Identification of Pitting on Sample Surface after Testing}

Figure 7 shows the metallographic analysis of pitting found in the AISI 317L stainless steel samples after conducting the polarization assays in a solution of $3.5 \%$ (\% mass) sodium chloride solutions in the absence and presence of propargyl alcohol at 25,40 and $55^{\circ} \mathrm{C}$.

Extensive pitting corrosion of the steel materials is very common in solutions that contain high concentrations of chlorides. Considering this fact, the objective is to show the increase in the size and shape of pitting through the parameters presented in Table 2, where the addition of propargyl alcohol reduced the corrosive attack when experiencing high temperatures.

The pitting formed after the test at $55^{\circ} \mathrm{C}$ without the use of the corrosion inhibitor (more critical condition) has a much larger size, 458 times, and are present in a larger quantity compared to those found in the test made in the same temperature using the propargyl alcohol in the solution, with approximately when compared to the tests done at $25^{\circ} \mathrm{C}$ and $40^{\circ} \mathrm{C}$ the difference in pitting size formed at $55^{\circ} \mathrm{C}$ is even greater. In the most critical condition, the size of the pitting is 18 and 17 times higher than the other temperatures without a corrosion inhibitor of $25^{\circ} \mathrm{C}$ and $40^{\circ} \mathrm{C}$, respectively.

\section{CONCLUSIONS}

The following conclusions may be drawn:

- In the potentiodynamic cyclic test, the addition of propargyl alcohol in the $3.5 \%$ of sodium chloride solution at each temperature analyzed increases the corrosion resistance of the studied steel, increasing the pitting potential and increasing the material passivation interval;

- With the optical microscope use, it is possible to observe the pitting presence in all the situations studied in the potentiodynamic cyclic tests, however the quantity and the size of the same increased in the corrosion inhibitor absence and also, according to the temperature elevation, the test specimen being at $55^{\circ} \mathrm{C}$ without inhibitor being the most affected;

- Addition of the propargyl alcohol in the sodium chloride solution reduces the intensity of pitting formation on the passivated surface. 


\section{REFERENCES}

I Fink JK. Oil field chemicals, New York: Gulf Professional Publishing; 2003.

2 Lo KH, Shek CH, Lai JKL. Recent developments in stainless steels. Materials Science and Engineering: R: Reports. 2009;65(4-6):39-I04. http://dx.doi.org/10.1016/j.mser.2009.03.00I.

3 Mainier FB, Farneze HN, Serrão LF, Oliveira BT, Nani BF. Performance of stainless steel AISI 3I 7L in Hydrochloric acid with the addition of propargyl alcohol. International Journal of Electrochemical Science. 2018; 13:3372-338I. http://dx.doi.org// 0.20964/ 2018.04.02.

4 ASTM International. ASTM A38006: Standard practice for cleaning, descaling, and passivation of stainless steel parts, equipment, and systems. West Conshohocken: ASTM International; 2006.

5 Mudali KU, Pujar MG. Corrosion of austenitic stainless steels: Mechanism, mitigation and monitoring 3. Pitting corrosion of austenitic stainless steels and their weldments. UK: Woodhead Publishing Limited, 2002.

6 Roberge PR. Handbook of corrosion engineering. New York: McGraw-Hill Education; 2002.

7 Magnabosco R, Alonso-Falleiros N. Sigma phase formation and polarization response of UNS S3 I 803 in sulfuric acid. Corrosion Science. 2005;6I:807-8I4. http://dx.doi.org/I0.5006/I.32782I 5.

8 Magnabosco R, Alonso-Falleiros N. Pit morphology and its relation to microstructure of $850{ }^{\circ} \mathrm{C}$ aged duplex stainless steel. Corrosion Science. 2005;6I:130-136. http://dx.doi.org// 0.5006/I.3278I67.

9 Calle LM, MacDowell LG, Vinje RD. Electrochemical evaluation of stainless steels in acidified sodium chloride solutions. New Orleans: NASA; 2004. [cited 2020 Mar 3]. Available at: https://ntrs.nasa.gov/search.jsp

I0 ASTM International. ASTM G6 I-86: Standard test method for conducting cyclic potentiodynamic polarization measurements for localized corrosion susceptibility of iron, nickel, or cobalt-based alloys. West Conshohocken: ASTM International; 2009.

Received: 5 Mar. 2020

Accepted: 25 Mar. 2020 